\title{
A IMPORTÂNCIA DO TEXTO CONSTITUCIONAL NO PROCESSO DE POSITIVAÇÃO DE NORMAS
}

Tiago Cappi Janini ${ }^{1}$

Amanda Juncal Prudente ${ }^{2}$

\section{Resumo:}

Este estudo busca demonstrar a importância do texto constitucional na Teoria Comunicacional do Direito. Parte-se do pressuposto que a linguagem é essencial ao conhecimento. Com o movimento do Giro Linguístico, a linguagem torna-se o centro e o objeto dos estudos filosóficos. Por ser o Direito um fenômeno linguístico, posto que formado essencialmente por palavras, desenvolve-se a Teoria Comunicacional do Direito e o Constructivismo LógicoSemântico, que têm como premissa interpretativa o direito como texto. Nesse percurso, objetiva-se demonstrar que o texto mais importante no sistema jurídico é a Constituição, responsável por validar todo o processo produtor de normas jurídicas.

Palavras-chave: Giro Linguístico; Constructivismo Lógico-Semântico; Teoria Comunicacional do Direito; Processo de positivação de normas; importância da Constituição.

\section{THE IMPORTANCE OF THE CONSTITUTIONAL TEXT IN LAW STANDARDS AFFIRMATION}

\begin{abstract}
:
This paper aims to present the importance of the constitutional text in Communicational Theory of Law. It is assumed that language is essential to knowledge. With the movement of the Linguistic Turn, language becomes the center and object of philosophical studies. As Law is a linguistic phenomenon, once formed essentially by words, Communicational Theory of Law and Logic-Semantic Constructivism develops from the assumption of law as text. Through this path it's purposed to demonstrate that the most important text in the juridical system is the Constitution, responsible for validating the whole juridical standards creational proceedings.
\end{abstract}

\footnotetext{
${ }^{1}$ Mestre e Doutor em Direito do Estado pela Pontifícia Universidade Católica - PUC São Paulo. Professor no Centro Universitário Salesiano de São Paulo - UNISAL. Endereço eletrônico: tiagocappi @ yahoo.com.br

${ }^{2}$ Bacharel em Direito pela Universidade Estadual do Norte do Paraná-UENP. Mestranda na linha de pesquisa Estado e Responsabilidade pela Universidade Estadual do Norte do Paraná-UENP. Advogada. Endereço eletrônico: amandajuncalprudente@ yahoo.com.br
} 
Keywords: Linguistic Turn; Logic-Semantic Constructivism; Communicational Theory of Law; Law standards affirmations; Importance of the Constitution.

\section{Introdução}

Objetiva-se, neste trabalho, demonstrar a importância do texto constitucional no processo de produção normativo. Para isso, finca suas premissas na Teoria Comunicacional do Direito e no Constructivismo Lógico-Semântico.

Parte-se do pressuposto que direito é texto, é linguagem, para responder ao seguinte questionamento: Qual a importância no texto constitucional na edição e interpretação das demais normas que formam o ordenamento jurídico pátrio?

Após identificar a evolução da filosofia da linguagem com o movimento do Giro Linguístico, em que se eleva o posto da linguagem, qualificando-a como criadora da realidade, estuda-se o direito como um fenômeno linguístico. Nesse contexto, observam-se dois corpos de linguagem: o Direito Positivo e a Ciência do Direito, cada um portador de um tipo de discurso próprio.

Apresentadas as características dos textos do Direito Positivo e da Ciência do Direito, dedica-se ao direito como um fenômeno comunicacional. Assim, tem-se a distinção entre o enunciado prescritivo, estrutura linguística que forma o ordenamento, e a norma jurídica em sentido estrito, resultado da interpretação dos textos jurídicos, que transmite a mensagem deôntica pretendida pelo direito.

Diante da clássica divisão entre ser e dever ser, identifica-se o processo de positivação de normas como método de aplicação visando regulamentar as condutas intersubjetivas, obtendo-se, ao seu final, as normas com graus máximos de individualidade e concretude. Essas normas são as responsáveis por direcionar, com maior precisão, os comportamentos humanos, isto é, influenciam mais diretamente o mundo do ser.

Nesse contexto, valendo-se do método dedutivo e da pesquisa bibliográfica, a hipótese defendida pauta-se na importância do texto constitucional no processo de positivação das normas. O percurso do intérprete na formação das cadeias normativas deve sempre se iniciar com os enunciados que formam a Constituição. Eis a pretensão deste trabalho, verificar a força normativa das normas constitucionais dentro do sistema jurídico, tendo como fundamento a Teoria Comunicacional do Direito e o Constructivismo Lógico-Semântico. 


\section{A linguagem como elemento constituidor da realidade}

No começo do século XX, iniciou-se uma nova era filosófica, cujo problema central é a linguagem. Com o movimento do linguistic turn (reviravolta linguística; giro linguístico) entendeu-se que não se pode filosofar sem antes filosofar sobre a linguagem, pois este é o "momento necessário constitutivo de todo e qualquer saber humano, de tal modo que a formulação de conhecimentos intersubjetivamente válidos exige reflexão sobre sua infraestrutura linguística” (OLIVEIRA, 1996, p. 13).

Nesse cenário, a linguagem ganha lugar de destaque, deixando-se de lado as questões filosóficas relativas ao ser e à consciência. Os pensadores começam a ver a linguagem como elemento essencial ao conhecimento e à realidade, e não mais um simples instrumento para representar as coisas. Com essa nova visão linguística do mundo, não se fala mais em uma relação sujeito-objeto de forma direta, em que as palavras tinham um vínculo natural com a essência das coisas que representavam, como se previa na chamada Filosofia da Consciência.

Eugenio Coseriu observa que os problemas da linguagem foram, durante muitos séculos, secundários ou ocasionais para a filosofia; fazia-se "filosofia com a linguagem, mas nunca sobre a linguagem" (1982, p. 45, grifo do autor). Porém, a partir do giro linguístico, a linguagem torna-se problema fundamental da filosofia.

O ser humano é cercado por um ambiente que requer algum tipo de ajuste intelectual para que possa viver bem. Transforma esse caos em um mundo dotado de certa interpretação. "Dando sentido às coisas que o cercam, interpretando-as, o ser humano pode viver (ou, no mínimo, sobreviver). Quer dizer, o ser humano reconhece as coisas, 'entende-as', sabe valerse delas, para seu benefício" (HEGENBERG, 2001, p. 25). Visando a essa finalidade, o sujeito cognoscente apreende um objeto por meio de atos de percepção e de julgamento para, então, emitir enunciados sobre suas conclusões.

O mundo físico existe como um caos que há de ser organizado e compreendido pelo homem. Essa descrição e conhecimento, porém, só são possíveis pela linguagem. Só se tem acesso à realidade por meio de sua configuração linguística. Em termos mais rigorosos, a linguagem é o meio que permite ao ser humano conhecer, descrever e ordenar a realidade.

Perspicazmente observou Vilém Flusser que o conhecimento, a realidade e a verdade

Rev. de Argumentação e Hermenêutica Jurídica | e-ISSN: 2526-0103| Goiânia| v. 5 | n. 1 | p. 36-54 | Jan/Jun. 2019 
são aspectos da língua (2004, p. 34). Sem a língua, portanto, não há o conhecimento, a realidade e a verdade. Por isso, propagou-se a ideia de que a linguagem cria a realidade. Coseriu aduz que "a existência das coisas só pode ser constatada a partir da linguagem" (1982, p. 26). Manfredo Araújo de Oliveira noticia a linguagem como condição necessária para a existência do mundo: "não existe mundo totalmente independente da linguagem, ou seja, não existe mundo que não seja exprimível na linguagem” (1996, p. 13). Lenio Streck afirma que "Sem linguagem não há mundo enquanto mundo. Não há coisa alguma onde falte a palavra. Somente quando se encontra a palavra para uma coisa é que a coisa é uma coisa" (2004, p. 196). De acordo com Castanheira Neves “o mundo-realidade sem a linguagem que de qualquer modo o diga ou se lhe refira (que dele ou para ele diga algo) seria um acervo absolutamente extensivo de uma indeterminação irracional” (2003, p. 249). Lourival Vilanova reconhece que o conhecimento só é obtido por meio da linguagem: "Mediante a linguagem fixam-se as significações conceptuais e se comunica o conhecimento. O conhecimento ocorre num universo-de-linguagem e dentro de uma comunidade-do-discurso" (1997, p. 37-8). João Adeodato enfatiza: “a linguagem literalmente 'faz' o mundo real e constitui o próprio ser humano" (2013, p. 13, grifo do autor). A realidade, portanto, só é acessível ao conhecimento humano por meio da linguagem.

Sucede que o termo realidade é utilizado de maneira ambígua, referindo-se à realidade trazida pelas palavras e à realidade do mundo físico. Vilém Flusser, porém, caracteriza a realidade dos dados brutos como palavras in statu nascendi (2004, p. 40). Dito de outra forma, o mundo físico, embora ainda não descrito em linguagem, está apto a ser e só assim chegará ao nosso conhecimento. Os dados brutos não seriam de fato realidade, e sim potencialidade.

A importância que a linguagem tem para a realidade apreendida pelo homem pode ser descrita por um exemplo. Até pouco tempo atrás, Plutão pertencia à classe dos planetas. Hoje, ao se relacionarem os planetas, deve-se excluir Plutão. E por quê? Simplesmente porque foram alterados os critérios que permitem classificar os objetos como planetas. Nenhuma modificação teve a realidade do mundo físico, pois a massa, a atmosfera e a órbita do explaneta continuam as mesmas, apenas a linguagem que conota planeta é que foi substituída. Com a nova classificação, Plutão tornou-se um “planeta-anão".

Em suma, a Filosofia da Linguagem parte do pressuposto que o homem habita um 
mundo que só existe para ele em virtude da linguagem.

\section{Direito e a virada linguística}

Hodiernamente, portanto, surge uma nova fase filosófica em que a linguagem alcançou o status de elemento essencial do conhecimento. É pela linguagem que se compreende a realidade. Essa metodologia atinge o direito. Sabe-se que o direito tem por finalidade regular condutas humanas. Essa tarefa é realizada por meio de ordens prescritas em textos. "Se suprimimos as palavras, suprimimos automaticamente o direito" (BELLO, 2011, p. 173).

Assim, afirma-se que direito é texto; é linguagem: “A prova palpável de que o direito $e ́$ texto está em que todo ordenamento jurídico é suscetível de ser escrito, isto é, de ser convertido em palavras. [...] O direito é linguagem no sentido de que sua forma de expressão consubstancial é a linguagem verbalizada suscetível de ser escrita”. (ROBLES, 2005, p. 02, grifo do autor). Por isso Paulo de Barros Carvalho pensa "que nos dias atuais seja temerário tratar do jurídico sem atinar a seu meio exclusivo de manifestação: a linguagem" (2008, p. 162).

Diante dessa perspectiva, desenvolveram-se, em especial, duas teorias jurídicas que iniciam seus estudos a partir da constatação que o direito é linguagem e só por meio de linguagem se manifesta. Na Espanha, Gregorio Robles idealizou a Teoria Comunicacional do Direito, cujo pressuposto básico é observar o direito como "um sistema de comunicação entre os homens cuja missão imanente é dirigir a ação humana" (ROBLES, 2006, p. 152, grifo do autor). Em viés semelhante, desenvolveu-se o Constructivismo Lógico-Semântico no Brasil, estruturado e organizado por Paulo de Barros Carvalho a partir dos ensinamentos de Lourival Vilanova. Trata-se de um expediente metodológico que, utilizando-se de rígidos esquemas lógicos, visa amarrar os termos da linguagem, sem olvidar do plano do conteúdo, optando pelas significações mais adequadas à fidelidade da enunciação (CARVALHO, 2014, p. 04).

São duas teorias, com vários pontos em comum, que procuram garantir maior uniformidade e coerência ao discurso científico do direito. Ambas consideram a linguagem como constitutiva da realidade, tomando o texto como ponto essencial para a interpretação do direito. Aceita essa premissa, utilizam-se, para o estudo do direito, os mecanismos 
desenvolvidos pela linguística e pela semiologia. Assim, propõe-se o estudo do direito nos três planos fundamentais da semiótica: sintaxe, semântica e pragmática (CARVALHO, 2013, p. 107).

No plano sintático, a linguagem jurídica é analisada levando-se em conta a sua estrutura intranormativa, organizando os signos do texto normativo para que se tenha uma mensagem deôntica compreensível que traduza para a sociedade uma conduta como lícita ou ilícita, e também a relação entre as normas jurídicas. O conhecimento da linguagem jurídica ingressa no prisma semântico a partir do instante em que o intérprete designa significações aos vocábulos que compõem o texto normativo. Para completar a interpretação da linguagem jurídica, além do estudo do plano sintático e semântico, deve-se analisar o campo da pragmática, em que se investigam problemas atinentes à eficácia, à vigência e à aplicação das normas jurídicas.

\section{Direito Positivo e Ciência do Direito}

A primeira aproximação entre a Teoria Comunicacional do Direito e o Constructivismo Lógico-Semântico ocorre com a distinção entre o Direito Positivo e a Ciência do Direito. Ambos são fenômenos linguísticos. Com a reviravolta linguística "salienta-se a importância fundamental da linguagem para a ciência do direito, pois esta deve construir seu objeto sobre dados que são expressos pela própria linguagem, ou seja, a linguagem da ciência jurídica fala sobre algo que já é linguagem anteriormente a esta fala" (WARAT, 1995, p. 38).

Nesse sentido, Gregorio Robles diferencia ordenamento e sistema (2005, p. 07 e seguintes; 2006, p. 119 e seguintes). O ordenamento é o conjunto de textos jurídicos parciais (constituição, leis, regulamentos, sentenças, etc.) produzidos pelas autoridades competentes; é o texto jurídico bruto. Agora, o texto jurídico elaborado é o sistema, cuja finalidade é aperfeiçoar o ordenamento. O sistema também é formado por textos, porém construído pela ciência do direito a partir dos textos que formam o ordenamento.

Sob essa perspectiva o direito e a sua descrição são igualmente formados por linguagem. O direito positivo é um corpo linguístico. A partir dessa constatação observa-se que a linguagem é o modo-de-ser do direito. A ciência que o descreve o faz por intermédio de

Rev. de Argumentação e Hermenêutica Jurídica | e-ISSN: 2526-0103| Goiânia| v. 5 | n. 1 | p. 36-54 | Jan/Jun. 2019 
outro tipo de linguagem. Todos textos.

Posto isso, verifica-se que tanto o direito positivo quanto a ciência do direito são fenômenos linguísticos. Conforme esclarece Lourival Vilanova, “a expressão linguagem jurídica é ambígua. Refere-se a dois níveis de linguagem: a do direito positivo e a da Ciênciado-Direito que tem o direito positivo como objeto de conhecimento (dogmático)” (1997, p. 65). O direito positivo é um discurso linguístico prescritivo, compostos por enunciados linguísticos normativos num dado espaço territorial, cuja finalidade é comunicar aos seus destinatários padrões de comportamentos sociais. Por sua vez, a ciência do direito é formada por um estrato de linguagem descritiva que se destina a estudar o direito positivo.

Paulo de Barros Carvalho (2013, p. 32-33) apresenta profundas diferenças entre o discurso do direito positivo e o da ciência do direito, que podem ser sistematizadas da seguinte forma: (i) quanto ao tipo de linguagem: o direito positivo se vale da linguagem prescritiva, e a ciência do direito usa a linguagem descritiva; (ii) quanto à hierarquia das linguagens: o direito positivo é linguagem-objeto, e a ciência do direito é metalinguagem ${ }^{3}$; (iii) quanto à lógica: ao direito positivo corresponde a lógica deôntica, enquanto a ciência do direito tem a lógica apofântica; (iv) quanto à valência da linguagem: ao direito positivo aplicam-se os valores válido ou não-válido, e para a ciência do direito os valores são verdadeiro ou falso.

Aproximam-se as lições apresentadas por Gregorio Robles e por Paulo de Barros Carvalho. O ordenamento, conjunto de textos legislativos, está para ideia de direito positivo; assim como o sistema volta-se para a ciência do direito. O sistema tem por objeto o ordenamento, e a ciência do direito é metalinguagem e o direito positivo linguagem objeto.

O direito, portanto, cria suas realidades por meio da linguagem jurídica. Fato jurídico, norma jurídica, relação jurídica, fontes do direito, coisa julgada, etc. são institutos jurídicos que somente existirão mediante a formulação da linguagem jurídica. Conclui-se que a linguagem é condição necessária para o direito, pois sem linguagem não existe o direito positivo, como não há ciência do direito. É, portanto, com base nesta premissa (de que o mundo jurídico é construído num universo de linguagem) que o presente trabalho será

\footnotetext{
${ }^{3}$ Tomado o plano da hierarquia das linguagens, sempre que existir uma linguagem, encontra-se a opção de emitir outro enunciado linguístico discorrendo sobre ela. Nesse caso, podem-se reconhecer nos níveis de linguagem a linguagem-objeto, que é aquela da qual se fala, e a metalinguagem, utilizada para se falar da linguagem-objeto. Assim, a ciência do direito é uma metalinguagem de outra, o direito positivo, ou seja, a linguagem-objeto.
}

Rev. de Argumentação e Hermenêutica Jurídica | e-ISSN: 2526-0103| Goiânia| v. 5 | n. 1 | p. 36-54 | Jan/Jun. 2019 
desenvolvido.

\section{Norma jurídica e enunciado prescritivo}

Para a Teoria Comunicacional do Direito tanto o ordenamento como o sistema são conjuntos de proposições linguísticas. "O ordenamento é composto por disposições ou preceitos (mandatos da autoridade jurídica). O sistema é composto por normas jurídicas" (ROBLES, 2006, p. 142). Como o sistema tem a finalidade de construir o que é descrito pelo ordenamento, a norma jurídica acabada, vista como um enunciado linguístico completo de sentido, só é encontrada no sistema. É evidente que o sistema, para elaborar a norma, recorre ao ordenamento, com o intento de precisar todos os elementos que atribuem um sentido deôntico à norma. A norma é uma proposição de linguagem presente no sistema, que expressa o ordenamento. Conclui Gregorio Robles que o sistema e as normas que o integram resultam do labor construtivista da dogmática (2006, p. 142).

Observa-se que a proposição linguística da norma jurídica não se confunde com os enunciados linguísticos encontrados no ordenamento. São metalinguagem e linguagemobjeto, respectivamente. A norma encontra-se no âmbito do sistema, que fala do ordenamento.

Atento a essa distinção, Paulo de Barros Carvalho propõe a separação entre norma jurídica e enunciado prescritivo (2013, p. 36; 2008, p. 129; 2006, p. 20). Os enunciados prescritivos são as frases, estruturas linguísticas plenas de sentido, que integram os textos jurídicos em estado bruto. Formam seus artigos, parágrafos, incisos e alíneas. Possuem sentido, mas não uma significação deôntica completa. A norma jurídica, por sua vez, é a construção feita pelo intérprete a partir da leitura dos enunciados prescritivos. É nela que se encontra a mensagem deôntica em sua plenitude de sentido. Uma coisa é o texto bruto do direito positivo (Constituição Federal, leis, decretos, regulamentos, etc.); outra, a construção significativa elaborada a partir dele.

Por conseguinte, nem todo enunciado prescritivo forma uma norma jurídica. Para ser norma jurídica em sentido estrito, necessita-se de um mínimo de significação deôntica na forma de um juízo condicional. O simples enunciado do art. 121 do Código Penal matar alguém não atinge o objetivo de transmitir uma mensagem deôntica completa, permitindo,

Rev. de Argumentação e Hermenêutica Jurídica | e-ISSN: 2526-0103| Goiânia| v. 5 | n. 1 | p. 36-54 | Jan/Jun. 2019 
proibindo ou obrigando uma conduta. É necessário que o intérprete continue sua pesquisa e observe a pena atribuída ao fato: reclusão, de seis a vinte anos. A partir da união dessas orações é que se obtém a proposição normativa: se matar alguém, deve ser preso em reclusão, de seis a vinte anos.

Para transmitir a mensagem normativa, a norma jurídica é uma unidade lógica com um mínimo de significação que permite ao intérprete compreender a regulamentação das condutas humanas a partir dos textos do ordenamento. Assim, deve descrever um fato jurídico que implicará, caso ocorra no mundo fenomênico, a prescrição de efeitos jurídicos.

A norma jurídica é, portanto, um juízo hipotético-condicional, em que se vincula uma determinada consequência à concretização de um fato. A hipótese alude a um fato e o consequente estabelece os efeitos jurídicos que o acontecimento do fato irá propagar. Estrutura-se assim: se ocorrer o fato $F$, deve ser a relação jurídica $R$. Essa proposição articula-se em forma lógica de implicação: o antecedente implica o consequente.

Analisando separadamente cada membro da estrutura normativa, encontra-se no antecedente a descrição de uma situação fáctica de possível ocorrência no mundo. Confirmada a concretização desse evento na realidade, implica-se a conduta prescrita no consequente, isto é, instauram-se os efeitos jurídicos da relação jurídica desenhada na norma jurídica. Essa relação $R$ dar-se-á entre dois sujeitos-de-direito distintos. Por sua vez, a "relação $R$ é deôntica e se traduz por expressões deônticas: 'está proibido', 'está permitido', 'está obrigado'” (VILANOVA, 1997, p. 99).

Desse modo, o intérprete, a partir do contato com o ordenamento, produzirá normas jurídicas que transmitem mensagens deônticas plenas de sentido, cujo antecedente descreve um fato que implicará efeitos jurídicos, qualificando a conduta humana em permitida, proibida ou obrigatória.

\section{A realidade social e a realidade jurídica}

De tudo que fora até aqui escrito, destacam-se duas premissas defendidas: a linguagem cria a realidade e, por consequência, a realidade jurídica pressupõe uma linguagem que a instaure. Sem linguagem só há dados brutos que não emergiram para o conhecimento humano. Da mesma forma, fatos e efeitos jurídicos só nascem, vivem e morrem quando 
descritos em um corpo linguístico.

Sem uma linguagem jurídica específica que introduza no sistema do direito os acontecimentos sociais, não se pode falar em consequências jurídicas desses eventos. Poderão produzir efeitos sociais, morais e até mesmo religiosos, cada um portador de um discurso linguístico específico, mas distantes de serem jurídicos. Tome-se o casamento como exemplo. Num primeiro momento, conta-se a amigos e familiares que uma pessoa se casou (linguagem social). Nada de jurídico nesse relato aconteceu. Há apenas adventos sociais. Indo-se à igreja, confirma-se, nos documentos sacros, que em determinado dia e hora houve uma cerimônia religiosa de casamento naquele templo, gerando aí consequências religiosas (linguagem religiosa). Os efeitos jurídicos somente aparecerão com o efetivo relato desse evento em linguagem jurídica: a certidão de casamento registrada em cartório. Somente a partir de então é que o casamento torna-se um fenômeno jurídico.

Outra importante distinção acima apresentada é entre o Direito Positivo e a Ciência do Direito. São subconjuntos autônomos, que evoluem por meio de uma linguagem específica. Não se confundem. Tomando-se como critério diferenciador a comunicação, é possível encontrar três espécies distintas de discurso: (i) da realidade social em sentido amplo (diz-se em sentido amplo pois engloba diversas realidades distintas da jurídica: econômica, política, religiosa, etc.); (ii) da realidade do Direito Positivo (ordenamento); e (iii) da realidade da Ciência do Direito (sistema). São ambientes autônomos, que operam utilizandose um código comunicacional próprio, mas que admitem o intercâmbio entre si de informações, desde que a absorvam com sua linguagem.

A finalidade do Direito Positivo é regular a convivência humana, qualificando as condutas como lícitas ou ilícitas. Nos dizeres de Lourival Vilanova: "altera-se o mundo social mediante a linguagem das normas, uma classe da qual é a linguagem das normas do direito" (1997, p. 40). O ordenamento, por meio de sua linguagem, visa definir os comportamentos sociais seguindo determinada ideologia. Seu objeto, portanto, é a linguagem da realidade social. Retornando à hierarquia das linguagens, o Direito Positivo seria uma metalinguagem, ao passo que a linguagem da realidade social, a sua linguagem-objeto.

O objeto é sempre mais amplo do que se pode descrever e nunca poderá ser esgotado pela linguagem. Lourival Vilanova, tratando do conceito fundamental de uma ciência, ensina que não se consegue captar toda a multiplicidade do real: “A realidade é sempre mais rica em

Rev. de Argumentação e Hermenêutica Jurídica | e-ISSN: 2526-0103| Goiânia| v. 5 | n. 1 | p. 36-54 | Jan/Jun. 2019 
determinação que seu correspondente conceito, e este mais pobre que a intuição dessa realidade" (2003, p. 06-07).

A realidade social, portanto, possui maior abrangência que a realidade do Direito Positivo. É impossível o direito, por meio de textos jurídicos, disciplinar todos os comportamentos e ações humanas. Diante de um vasto campo de acontecimentos da realidade social, o direito seleciona quais condutas ou ações deseja regular. Trabalha, nesse momento, no eixo paradigmático de organização do discurso jurídico, em que o legislador possui uma ampla liberdade de escolha dos fatos sociais para imputar à sua ocorrência o surgimento de certas relações jurídicas (ARAUJO, 2005, p. 29-30). O legislador elege eventos sociais para integrar o antecedente das normas jurídicas, atribuindo-lhes um dos seguintes efeitos jurídicos: permitido, obrigatório ou proibido.

Ao criar as normas jurídicas, o legislador escolhe acontecimentos do mundo real e os juridiciza, fazendo-os adentrarem no campo do direito: "o fato se torna fato jurídico porque ingressa no universo do direito através da porta aberta que é a hipótese" (VILANOVA, 1997, p. 89). A linguagem jurídica traduz os acontecimentos do mundo social, imputando-lhes efeitos jurídicos. Deve-se alertar, todavia, que essa tradução não é perfeita, ou seja, o fato social não é idêntico ao fato jurídico, mesmo que tenha servido de suporte para a criação da norma jurídica.

Para Vilém Flusser (2004, p. 61), não existe uma perfeita tradução entre idiomas, pois cada língua possui uma personalidade própria, proporcionando uma realidade específica. Sendo assim, a tradução somente se daria de forma aproximada, uma vez que a realidade criada por duas línguas distintas não é a mesma. Roman Jakobson (2003, p. 71) aponta um interessante exemplo que serve para mostrar a dualidade das realidades criada por línguas distintas. A palavra "pecado" em russo é do gênero masculino e em alemão pertence ao feminino. Diante dessa diferença de gêneros da palavra "pecado", causava estranheza ao pintor russo Repin ver o "pecado" representado por uma mulher pelos artistas alemães, pois, para a realidade russa, "pecado" era masculino. Porém, bastava conhecer que a realidade dos alemães para "pecado" pertencia ao conjunto dos objetos femininos.

O direito positivo, ao traduzir a realidade social, o faz de forma aproximada e cria suas próprias realidades. O fato social "morte", ao ingressar no mundo do direito, é traduzido por "homicídio doloso", "homicídio culposo", "legítima defesa", "sucessão", "ausência", 
"pensão", "ITCMD (imposto sobre transmissão causa mortis e doação)", etc. Dessa forma, o direito positivo mantém uma ampla conversação com a linguagem social, permitindo o seu ingresso no mundo do direito por meio das normas jurídicas.

O que se pretende deixar evidente é que há dois subconjuntos distintos: o da realidade social e o da realidade jurídica, cada qual formado por uma linguagem específica. Essa diferença já havia sido percebida por Hans Kelsen, que separou o mundo do ser do dever ser (1998, p. 06). O dever ser relaciona-se com o ser, pois seu escopo é regular os comportamentos humanos. Todavia, as comunicações produzidas pelo ordenamento jurídico somente são digeridas pela realidade social, por meio de sua linguagem própria. Os subsistemas se comunicam, trocam informações, mas cada um as processa internamente, segundo sua linguagem.

\section{Processo de positivação de normas}

Já se sabe que a finalidade precípua do direito é regular as condutas humanas. Entretanto, há uma distância intransponível entre o mundo do ser e o do dever ser. Como sistemas distintos e autônomos que são, operam com suas próprias estruturas linguísticas, sem que um possa, no outro, diretamente interferir. Pode haver irritação entre eles, só que a informação vinda do ambiente somente deve ser processada por operações comunicacionais internas de cada sistema. Tal situação é vista quando analisados o Direito Positivo e a realidade social. $\mathrm{O}$ direito por mais que tente influenciar os comportamentos sociais nem sempre logra êxito. O simples fato de uma norma jurídica proibir seguir quando o sinal estiver vermelho não significa que esse padrão será aceito e seguido por toda a sociedade. Veja-se o esforço feito pelo sistema jurídico para se evitar que motoristas dirijam alcoolizados. Mudanças na legislação, criando penas mais severas, além de recorrentes condenações na esfera penal e administrativa, não evitam a prática da conduta.

Observa-se, então, que a linguagem do Direito Positivo não atinge diretamente a região das condutas ônticas. Tangencia-as. Os comportamentos humanos são direcionados pelo direito, apesar dos inúmeros esforços jurídicos que se criam para que o ser humano aja de determinada maneira, não significa, porém que assim ele procederá. Ora, se a finalidade do direito é regular as condutas sociais, como fazer se ele não as atinge diretamente?

Rev. de Argumentação e Hermenêutica Jurídica | e-ISSN: 2526-0103| Goiânia| v. 5 | n. 1 | p. 36-54 | Jan/Jun. 2019 
Para isso, o direito utiliza-se do processo de positivação que consiste no percurso que o direito realiza a partir de concepções abrangentes, previstas nas normas gerais e abstratas, para atingir os níveis mais próximos da região material das condutas intersubjetivas (CARVALHO, 2006, p. 226). Construção semelhante é proposta por Gregorio Robles ao descrever o fenômeno da concreção: "Na medida em que se vai descendo a pirâmide normativa, passa-se do mais geral ao mais particular, produz-se um processo de concreção ou determinação do fenômeno normativo, até chegar, finalmente, aos atos individualizados de aplicação" (2006, p. 239).

Conforme se observa, a influência do mundo do dever ser sobre o universo ontológico depende da aplicação da norma geral e abstrata produzindo uma norma individual e concreta. Somente com a produção desse instrumento normativo é que o direito positivo irá direcionar o comportamento humano. É nesse sentido que conclui Paulo de Barros Carvalho: "Uma ordem jurídica não se realiza de modo efetivo, motivando alterações no terreno da realidade social, sem que os comandos gerais e abstratos ganhem concreção em normas individuais." (2006, p. 227). É a norma individual e concreta, portanto, que provoca maiores irritações na realidade social.

Entretanto, o fenômeno de positivação de normas não é de todo simples. O direito é complexo, composto por inúmeras normas jurídicas, porém, finitas, que vão se (re)produzindo e desencadeando novos fluxos normativos conforme o direito exige. A interconexão entre normas não é visualizada facilmente. Pode haver uma conduta que desencadeie efeitos civis, penais, administrativos, ambientais, etc. Seriam várias normas incidindo ao mesmo tempo e sobre um único fato. Para estudar esses fenômenos jurídicos, o cientista do direito deve realizar cortes, partindo do texto do direito, separando as normas e os fatos e descrevendo os seus efeitos.

O subsistema do direito é composto por diversas normas que se sucedem logicamente, criando inúmeras cadeias normativas, cada uma desenvolvendo seu próprio processo de positivação. Forma-se o fluxo de causalidade jurídica, isto é, o "cordão, pontoposponto, formado de normas que se orientam em intermináveis cadeias normativas e que se difundem nas mais diversas direções, compondo múltiplas séries causais que se entrelaçam, em sua urdidura, os diversos ramos do direito" (SANTI, 2004, p. 152).

A corrente normativa, no seu desenrolar, pode ser interrompida de diversas formas.

Rev. de Argumentação e Hermenêutica Jurídica | e-ISSN: 2526-0103| Goiânia| v. 5 | n. 1 | p. 36-54 | Jan/Jun. 2019 
Tal ruptura pode ensejar novo processo de positivação, compondo fluxos normativos diversos, ou simplesmente encerrar a produção normativa. Existe a norma geral e abstrata que proíbe matar alguém. Ocorrendo esse evento na realidade social, aplica-se a norma jurídica, culminando com uma norma individual e concreta estipulando uma sanção penal ao autor do delito. Encerra-se uma cadeia normativa. Acontece que a sentença penal condenatória pode produzir consequências civis, dando ensejo ao surgimento de outro processo de positivação de normas. Decorrem distintos efeitos jurídicos, como excluir da sucessão o herdeiro que participa de homicídio contra a pessoa cuja sucessão se tratar. Além dos resultados penais e civis, a mesma sentença ainda pode ensejar consequências administrativas, tal como a perda do cargo pelo funcionário público condenado.

O direito sob a perspectiva de ser um fenômeno comunicacional é composto por diversas mensagens deônticas que qualificam as condutas humanas como lícitas ou ilícitas. Para atingir graus máximos de efetividade e, com isso, direcionar a realidade social, as normas jurídicas são aplicadas, desencadeando novas normas jurídicas, até se atingir maiores níveis de concretude e individualidade. "Cada norma provém de outra norma e cada norma dá lugar, ao se aplicar à realidade, a outra norma" (VILANOVA, 1997, p.164). É o sistema jurídico visto como um fenômeno autopoiético, gerando a si mesmo, por meio de normas jurídicas.

O direito é um sistema complexo, em constante evolução, com normas jurídicas sucedendo normas jurídicas. Já observara Norberto Bobbio que "as normas jurídicas nunca existem isoladamente, mas sempre em um contexto de normas com relações particulares entre si” (1997, p. 19). Constantemente ingressam normas no sistema, sejam elas abstratas ou concretas; individuais ou gerais. A cada instante um texto jurídico é produzido. Contratos são elaborados. Leis, promulgadas. Proferem-se sentenças e acórdãos.

Tomando-se como pressuposto que a norma jurídica é criada a partir dos textos que formam o ordenamento, a cada momento que um novo texto é produzido, normas jurídicas podem ser criadas, compondo o sistema. Por isso Gregorio Robles afirma que "A norma jurídica nunca aparece isolada; é parte de amplas redes de proposições linguísticas similares, que por sua vez são resultado da reconstrução hermenêutica do texto bruto do ordenamento" (2005, p. 11, grifo do autor).

Para identificar os comportamentos humanos como lícitos ou ilícitos, o intérprete

Rev. de Argumentação e Hermenêutica Jurídica | e-ISSN: 2526-0103| Goiânia| v. 5 | n. 1 | p. 36-54 | Jan/Jun. 2019 
analisa o texto jurídico, ordenando-o em normas jurídicas, estabelece os critérios de conexão entre as normas, qualificando-as como válidas ou inválidas, e atribui os conteúdos significativos dos termos utilizados no ordenamento. É um labor constructivista.

\section{O texto constitucional no processo de positivação de normas}

O ponto de partida para o estudo das normas jurídicas é o contato com a linguagem do direito. A Ciência do Direito, ao iniciar seus estudos, depara-se, em um primeiro momento com os textos que compõem o ordenamento jurídico. "Nenhuma pessoa lograria construir o ato hermenêutico, oferecendo sentido ao produto legislado, sem iniciar seu trabalho pelo plano da expressão ou da literalidade textual, suporte físico das significações do direito" (CARVALHO, 2011, p. 34).

A partir do ordenamento, o intérprete vai construindo as estruturas lógicas das normas jurídicas e atribui um conteúdo significativo para seus signos. Nesse labor inclui-se o cotejo entre as normas do sistema, principalmente para verificar sua validade. Ao elaborar um texto normativo, o sujeito competente deve seguir estritamente as diretrizes de uma norma de competência. Nessa norma encontra-se detalhado quem pode produzir o texto e como deve produzi-lo.

O direito é formado por linguagem, e sua positivação depende da produção de nova linguagem prescritiva; novos textos legislativos agregam-se ao ordenamento. A concretização do direito é sobremodo importante, principalmente no que tange à inter-relação entre o direito e os demais subsistemas sociais. É o processo de positivação que faz com que o homem aproxime a comunicação jurídica da comunicação social.

O processo de positivação deve sempre se iniciar a partir do texto constitucional. Todo ato produtor de normas tem de observar atentamente as diretrizes prescritas na Constituição. As normas de competência devem ser elaboradas com fundamento nos enunciados prescritivos constitucionais.

A evolução do direito constitucional, principalmente com a falência dos regimes autoritários e totalitários pelo mundo, fez com que surgissem Constituições com conteúdo recheado de direitos e garantias fundamentais dos cidadãos com a finalidade de protegê-los perante os abusos que poderiam ser cometidos pelo Estado. A Constituição da República 
Federativa do Brasil de 1988 é um desses tipos de texto prolixo.

A Constituição atualmente é vista como o centro do sistema jurídico, com ampla força normativa, que se irradia para todo o ordenamento. É o princípio da supremacia da Constituição, que a coloca no topo do ordenamento, e lhe confere validade. Assim, as normas infraconstitucionais devem ser compreendidas e aplicadas conforme o conteúdo do texto constitucional, efetivando os valores nele constantes.

Ao se produzir um novo texto legal sem olhar para as indicações constitucionais, esse texto deve ser rechaçado do ordenamento; não se encontra apto a integrá-lo. A forma para excluir esse texto é descrita pelo próprio direito. Nesse caso, deve-se qualificá-lo como inconstitucional. A inconstitucionalidade de um comando legal é uma das maneiras de declarar que ele é inválido, ou seja, não está apto a desencadear efeitos jurídicos.

O processo de positivação de normas não pode conter, em seu fluxo normativo, normas, de quaisquer espécies, que desrespeitem o conteúdo dos enunciados que compõem a Constituição. Se houver, os efeitos jurídicos aí desencadeados não são válidos; precisam ser declarados inconstitucionais e retirados do ordenamento. A conduta imposta pela norma individual e concreta não é aquela eleita pelo ordenamento como lícita.

\section{Conclusões}

A Teoria Comunicacional do Direito e o Constructivismo Lógico-Semântico são metodologias que se assemelham e procuram descrever a complexidade do fenômeno jurídico. Partem da premissa de que o direito é texto, formado por linguagem. Condição que deve ser levada em consideração pelos juristas quando estiverem diante dos diversos ordenamentos legais. Não é possível especular acerca do direito sem antes considerá-lo texto.

A finalidade do ordenamento é regular as condutas sociais. Como não se comunicam diretamente a realidade social e a jurídica, a positivação das normas é o método eleito pelo sistema para chegar o mais próximo possível de materializar os comportamentos escolhidos pelo direito como lícitos. O processo de positivação de normas consiste no fluxo normativo cuja cadeia se encerra com a produção de uma norma individual e concreta, especificando a conduta como permitida, proibida ou obrigatória.

É importante constatar que o ordenamento atribuiu força significativa ao texto

Rev. de Argumentação e Hermenêutica Jurídica | e-ISSN: 2526-0103| Goiânia| v. 5 | n. 1 | p. 36-54 | Jan/Jun. 2019 
constitucional. A Constituição é o texto de maior importância no ordenamento. Ela contém as diretrizes que os atos ponentes de normas devem rigidamente seguir, sob pena de serem declarados inconstitucionais e, com isso, serem excluídos do ordenamento. Sem atentar para os dizeres do texto constitucional, as normas produzidas não são aptas a desencadearem efeitos, prejudicando o processo de positivação de normas.

Assim, ao se iniciar a produção de novas normas no sistema, o intérprete/aplicador deve sempre respeitar o disposto no texto constitucional. Caso assim não atue, o texto elaborado deve ser retirado do ordenamento, por vícios de inconstitucionalidade.

\section{Referências bibliográficas}

ADEODATO, João Maurício. Retórica analítica como metódica jurídica. Revista Argumenta, Jacarezinho/PR, n. 18, p. 11-29, 2013.

ARAUJO, Clarice Von Oertzen de. Semiótica do direito. São Paulo: Quartier Latin, 2005.

BELLO, Héctor López. Derecho, lenguaje y comprensión: la dimensión hermenéutica del texto jurídico. In: ROBLES, Gregorio; CARVALHO, Paulo de Barros (coords.). Teoria comunicacional do Direito: diálogo entre Brasil e Espanha. São Paulo: Noeses, 2011. p.

BOBBIO, Norberto. Teoria do ordenamento jurídico. 9. ed. Brasília: Editora Universidade de Brasília, 1997.

CARVALHO, Paulo de Barros. Algo sobre o constructivismo lógico-semântico. In: (coord). Constructivismo lógico-semântico. v. I. São Paulo: Noeses, 2014. p. 03-11.

Curso de direito tributário. 25. ed. São Paulo: Saraiva, 2013.

Regras técnicas ou procedimentais no direito tributário. In: ROBLES, Gregorio, CARVALHO, Paulo de Barros (coords.). Teoria comunicacional do Direito: diálogo entre Brasil e Espanha. São Paulo: Noeses, 2011. p. 33-45.

Direito tributário, linguagem e método. São Paulo: Noeses, 2008.

Rev. de Argumentação e Hermenêutica Jurídica | e-ISSN: 2526-0103| Goiânia| v. 5 | n. 1 | p. 36-54 | Jan/Jun. 2019 
. Direito tributário: fundamentos jurídicos da incidência. 4. ed. rev. e atual. São

Paulo: Saraiva, 2006.

CASTANHEIRA NEVES, A. O actual problema metodológico da interpretação jurídica I. Coimbra: Coimbra Editora, 2003.

COSERIU, Eugenio. O homem e sua linguagem. Rio de Janeiro: Presença; São Paulo: Universidade de São Paulo, 1982.

FLUSSER, Vilém. Língua e realidade. São Paulo: Annablume, 2004.

HEGENBERG, Leônidas. Saber de e saber que: alicerces da racionalidade. Petrópolis: Vozes, 2001.

JAKOBSON, Roman. Lingüística e comunicação. 19. ed. São Paulo: Cultrix, 2003.

KELSEN, Hans. Teoria pura do direito. 6. ed. São Paulo: Martins Fontes, 1998.

OLIVEIRA, Manfredo Araújo de. Reviravolta lingüístico-pragmática na filosofia contemporânea. 3. ed. São Paulo: Edições Loyola, 1996.

ROBLES, Gregorio. O direito como texto: quatro estudos de teoria comunicacional do direito. Barueri: Manole, 2005.

Teoría del derecho: fundamentos de teoría comunicacional del derecho. 2. ed. Madri: Civitas, 2006.

SANTI, Eurico Marcos Diniz de. Decadência e prescrição no direito tributário. 3. ed. rev. e ampl. São Paulo: Max Limonad, 2004

STRECK, Lenio Luiz. Hermenêutica jurídica e(m) crise. 5. ed. rev. e ampl. Porto Alegre: Livraria do Advogado, 2004.

VILANOVA, Lourival. As estruturas lógicas e o sistema do direito positivo. São Paulo: Rev. de Argumentação e Hermenêutica Jurídica | e-ISSN: 2526-0103| Goiânia| v. 5 | n. 1 | p. 36-54 | Jan/Jun. 2019 
Max Limonad, 1997.

Sobre o conceito de direito. Escritos jurídicos e filosóficos. v. 1. São Paulo: Axis Mundi, 2003. p. 01-78.

WARAT, Luis Alberto. O direito e sua linguagem. 2. ed. aum. Porto Alegre: Sergio Antonio Fabris Editor, 1995. 